\title{
What a patient can expect from a consultant psychiatrist
}

\author{
Michael Shooter
}

A psychiatrist needs youthfulness, sanctity, a welljudged sense of humour ... and the wisdom of the ages would be helpful, but I don't want to seem greedy.

This half-joking remark from the Specialist Adviser to a national mental health charity, sums up the dilemma every consultant faces from time to time: how to be all things to all people. What is more, it tunes in to our own sense of omnipotence. A recent review of ethics in psychiatry (Adshead, 1995) urged consultants to follow the four principles in practice: respect for the autonomy of the patient; beneficence (actively doing good); non-maleficence (avoiding doing harm); and the pursuit of justice - an incontestable but formidable remit.

Even more daunting is the realisation that there are potential clashes between and within these four principles. As Adshead points out, this usually happens when there is a conflict of responsibility. She quotes the example of the child psychiatrist's clinical obligations to maintain confidence, legal obligations to follow abuse procedures and ethical obligations to protect the vulnerable from every sense of danger; consultants will experience many more such conflicts in their own specialities. An unofficial trawl of 'consumer' opinion, via the Patients' and Carers' Liaison Group of the Royal College of Psychiatrists, confirms the list of perfectly appropriate but often seemingly contradictory expectations - a series of tightropes for the consultant to walk along, balancing rival needs and considerations on each side.

There would appear to be four tightropes, suspended over service issues, treatment issues, relationship issues, and personal issues, with three sets of balanced implications on each. The list is not exclusive, nor is any issue independent of the rest. While walking along one tightrope, the consultant must keep an eye on the others lest an upset on one brings the whole show down.

\section{Service issues - fairness: who is entitled to what, when and from whom}

\section{Economic efficiency v. therapeutic demands}

The consultant should advise the client, prior to admission, of the treatment approaches employed by the service, the existence of contracts, behaviour programmes, group and individual therapies.

The consultant should be willing to explore alternative forms of treatment, extracontractual referrals, arts therapies and other psychotherapies.

Patients' group representatives

Clearly, a consultant can be held responsible for much of the four elements that make up a patient's first impressions of the service: "speed of response; friendliness of response; understanding reaction, and a willingness to listen" (Howe, 1993), now enshrined in the Patients' Charter. But the consultant is often seen to represent what the service has to offer in a much wider sense and the Trust management may not be slow to encourage that perception.

Adshead defined justice as a sense of fairness that includes equality of opportunity, treatment and resources. There seems to be an assumption in some circles that these are synonymous and that

Mike Shooter, FRCPsych, is a Consultant in Child and Adolescent Psychiatry at the Gwent Comunity Health NHS Trust (Children's Centre, Nevill Hall Hospital, Brecon Road, Abegavenny, Monmouthshire NP7 7EG). He has a personal interest in working with chronically physically ill, dying and bereaved children. He is currently Deputy Registrar of the Royal College of Psychiatrists, Director of the Public Education Department and Chairman of the Patients' and Carers' Liaison Group. 
the dissemination of evidence-based information will ensure that services are not only more clinically effective, but also more cost-effective. Some would commend Oregon's proposed Medicaid plan in which consultants are obliged to place every treatment in rank order by rating each one as essential, very important or merely valuable. The NHS Executive's Register of CostEffective Studies may well one day prioritise psychiatric treatment in just such a way.

In the meantime, patients are entitled to expect that their consultant is financially educated and cooperative enough to ensure an equable spread of resources across specialities, and strong enough to fight their own particular corner. In the long run, consultants may be able to educate purchasers on the patients' behalf by showing, for example, that preventive measures such as parent-skills training are cost-effective, as well as clinically effective, for child, adolescent, adult, forensic and other psychiatric specialities, albeit generations down the line.

\section{Individual availability v. organisational structure}

Accessibility is always a difficult one. Perhaps the way forward would be to have a medical link line, with a qualified medic trained to assess the urgency of the call and able to act accordingly.

My doctor is generous with the frequency with which he sees me. He is always available.

Two manic depression sufferers

Faced with the monolithic structure of most services, it is the regular, face-to-face contact with an individual consultant psychiatrist that patients value most. And yet, just as the services themselves have had to be rationed, so the time of consultants is not infinitely expandable. Small wonder that many patients are dissatisfied with their doctor's availability (Barker et al, 1996).

Despite the relentless retreat into management, medicine is perhaps unique among the caring professions in not promoting its practitioners away from contact with the consumer; proper use needs to be made of such an asset. This means personal and private time, not just the public embarrassment of a ward round, however sensitively handled. It means being approachable in spirit as well as body and for emergency consultation between regular appointments.

There are some caveats, of course. Without being patronising, the Winnicottian 'good-enough parent' needs sometimes to frustrate demands and encourage the patient to find the answers within himself. A consultant should not need to give out private telephone numbers to convince a patient that care continues between sessions in a way that can be internalised and used by the patient in times of need.

So, too, the patient should be able to exercise choice. Female patients, at their most vulnerable, have a right to see someone of the same gender; patients from an ethnic minority have a right to be treated by someone with knowledge of and sensitivity to their particular needs. Often, however, that choice is illusory. Attention has been drawn to the subtle process by which patients need to tailor their symptoms to the style of the therapist; if they use a different language (in a broad sense) they risk being ignored or attacked.

\section{Clinical autonomy v. checks and balances}

Some patients are easily manipulated to express opinions that please someone they see as being in authority.

Officer of a mental health charity

I want us to be partners ... he must be aware of the power balance in the relationship and do his best to equalise it.

Hospital in-patient

Having established the sanctity of their relationship, only the patient and consultant may feel entitled to say whether it is working or not. It will be protected by such concepts as confidentiality and by a general assertion that medicine is an art form that is not susceptible to ordinary scientific audit.

Doctors must make decisions, give advice and offer assurance based on limited interpretation of limited evidence. Evidence that is gathered not only from the randomized trial but also - dare one say it - from raw clinical experience, complex patient biography, a telling phrase, or an inadvertent gesture.

Horton, 1995a

The patient should expect, however, that the relationship be open to question in many ways; to direct challenge and to the evaluation of impartial others. This includes detailed research projects, the importance of which may be revealed only when they are synthesised into a larger picture reflecting something about people as human beings, but which inform all good practice. It includes the continuous process of clinical audit, opening and closing the loop of examination and modification in the light of experience.

It must also include the complaints procedure. Not everyone would agree that many therapists allow themselves to be corrupted by the power invested in them but the possibility is there none the less. However assertive they may be, vulnerable patients need help to complain about those they feel have 
betrayed their fragile trust, or at the very least to move on to those they trust more.

\section{Treatment issues - individuality: how to balance general knowledge against individual experience}

\section{All-round ability v. depth of knowledge}

All too often the sufferer is referred to a general consultant who has little insight into the problems or little knowledge of current research into treatment approaches.

Eating disorders spokesperson

Each psychiatrist needs to offer a complete regime, including relaxation, counselling and other complementary therapies, when required.

Mental health service user

As the patient searches for help in managing the chaos of his life, so the psychiatrist refers to the specialist when he feels out of his depth in a litiginous world. Perhaps this is the simple admission that we can no longer find the hours to read all the literature. Perhaps it is because we are all looking for authority figures. At any rate, we seem to be approaching a profession in which everything is subject to expertise, "from mourning to making love" (Phillips, 1996).

This is compounded by attempts to standardise services in the face of overwhelming demands for treatment of intractable and often controversial problems. The concept of 'tiers of action', from primary care, through isolated secondary-tier experts, to a tertiary level of dedicated mental health teams and on to supra-regional, quaternary specialist units, can look suspiciously like a hierarchy of increasingly sophisticated work, rather than a picture of complementary packages of help for the patients on the receiving end. It has echoes in the debates between different types of treatment (organic $v$. talking cures, mainstream $v$. alternative therapy) and the exclusivity of those who practise them.

The challenge for the specialist is how to employ her expertise in such a way that enables rather than de-skills the remainder, at every level. Thus supported, both generalist and patient in turn can feel more confident in their own abilities, even at the expense of an occasional mistake. Perfection is a poor model; fallability is a necessary part of good counselling.

\section{Golden guidelines v. individual exceptions}

The consultant must treat the patient as an individual ... not as a schizophrenic, manicdepressive or anorexic.

Eating disorders representative

For years I was fobbed off with mood swings ... the term manic-depression was never mentioned ... because I was ignorant of my illness there was no way I could help myself.

Long-term in-patient, now in prolonged remission

One raft of reassurance for the generalist navigating the shifting seas of clinical psychiatry will be the Guidelines Programme currently being laid down by the Research Unit of the Royal College of Psychiatrists. With these in place, the patient can expect that her consultant has knowledge and experience of accepted wisdom within the profession.

Yet clinical guidelines are not uncontroversial. There are those who believe that the exercise of an individual's clinical judgement is just a cover for sloppy thinking, while others have criticised guidelines for breeding 'fools of doubt' who refuse to deviate from orthodox practice in the search for a creative solution. Still others worry that the golden guideline will rapidly become the legal precedent on which aberrant clinicians will be tested in court.

As the Patients' and Carers' Liaison Group has pointed out, too broad a series of guidelines could smother consultant intuition and discourage categorised patients from exercising their right to 'shop around' for alternative solutions.

Perhaps the most sensible and liberating compromise is to view psychiatry, like all medicine, as a series of concentric 'rings of uncertainty' (Seedhouse, 1991). Guidelines offer the clinician a way of practising 'safely' within each ring, while remaining flexible enough to cover several treatment options. They might even encourage some clinicians to stick with the difficult clients on the periphery, where they might learn as much from people as from research.

\section{Treating illness v. treating needs}

I need my psychiatrist to see me as a whole person with a unique life-style, not merely a collection of symptoms treatable with drugs.

It's no good telling me to give up drinking tea and be more active and go to bed later. If I could do these things I wouldn't be ill!

Two Manic Depression Fellowship members

Having addressed the issues of what services have to offer, what evaluation can patients expect of 
what is done to them? If there was disagreement before, here the problems really start!

Consultants have come under increasing pressure, from both purchasers and patients, to produce outcome measures that are valid, reliable, responsive to fine clinical change and couched in an appropriate format. Traditional measures of service use, such as hospital readmission rates and length of stay, often reflect service policy and provision in a self-fulfilling manner, rather than giving us real information about the impact of treatment on patients. As a result, selfrating has become increasingly popular but reveals enormous discrepancies between the opinions of patients and their doctors.

What really matters in the 20th century is how the patient feels, rather than how doctors think they ought to feel on the basis of clinical measurements. Symptoms response or survival rates are no longer enough.

Bowling, 1991

The consultant who is receptive to quality of life issues is likely to find that having a roof over your head, enough money to live on, a meaningful day and the support of family and friends are just as important as pure relief from symptoms and the availability of expertise. What is more, just as with chronic physical illnesses like epilepsy or diabetes, perfect scores on classical criteria may have to be sacrificed in favour of overall well-being.

None of this is any good, of course, unless services change in response. Consultants will not take kindly to being loaded with responsibility for how patients feel without the power to make a difference. Patients themselves will not comply with what they see as irrelevant treatment rather than something which they can understand, share in and truly appreciate.

\section{Relationship issues - empowerment: working towards the patient's autonomy}

\section{Patient's v. doctor's agendas}

I want my psychiatrist to treat me as an equal partner in the quest for recovery.

Mental health charity council member

How can I practise self-management if I don't know what to manage?

Recent in-patient

Most relationships have a shape to them, a beginning, a middle and an end, even if it is only for each period of treatment in a chronic, relapsing-remitting illness.
It is important that the consultant recognises where he is on that time curve because the same behaviour, such as failure to turn up for a session, may have very different meanings at different points. The tasks will be very different at each stage.

One of the earliest of those tasks will be a decision, implicit or explicit, about agenda. Interventions have been broadly divided into the authoritative (prescriptive; informative; confrontational), in which the clinician takes responsibility on behalf of the patient and guides his behaviour or gives instructions, and the facilitative (cathartic; catalytic; supportive), in which the clinician enables patients to take on more responsibility for themselves by eliciting self-learning (Heron, 1991).

This is a matter of 'horses for courses', in which patients can expect a measure of agreement on what is most needed at what time. If the consultant gets it wrong, then she and the patient may enter a circular dance of misunderstanding in which a patient can feel cherished while continuing to flounder for lack of advice, or receive wisdom but not feel any better. The twin key issues are power and responsibility and these will shift together, according to need, from the consultant's hands, to shared acceptance, to patient autonomy in any healthy relationship.

At one end of this spectrum, psychiatrists have a special power - they can shut people away. Failure to take on such emergency power is to deny the patient's right to care, whatever they might say at the time. At the other end, patients have a responsibility to take back power as they get better, though some might blame bad genes or an unhappy childhood for not doing so. Always, the consultant should work towards ultimately re-investing control in the patient and boosting self-esteem. To that extent, in the course of the relationship, the patient is taken through a real developmental process.

\section{Integrity $\mathrm{v}$. sharing}

Consultants should avoid acting as though families had no rights ... they should be more open about their intentions and not seek shelter behind spurious claims of patient confidentiality.

Officer of a national charity

I'm sure he shouldn't speak to them over your head.

Out-patient with past admissions

When patients come for help, they entrust us with the story of their lives. The secret of their suffering has become unbearable to keep. How the consultant handles that secret is part of the very stuff of therapy.

A recent editorial, quoting the Hippocratic oath, expressed serious worries that the introduction of information technology has allowed patients' 
details to be sent from one hospital to another by fax and unauthorised people to browse them at will (Horton, 1995b). It seems likely that the whole issue of confidentiality will become the substance of practitioner-patient review over the next few years. Once confidentiality is broken, how can any patient trust their doctor with the truth?

In the meantime, patients can expect that services in general and consultants as individuals will examine their own safeguards. If British Medical Association rulings are strictly adhered to, services cannot implicitly assume that information can be passed among professionals, even within multidisciplinary teams let alone outside to general practitioners, social workers or teachers, without patient consent. The wider family, whose involvement is so crucial to patient care, presents a particular problem.

In any contract with their consultant, most patients might be willing to accept provisos that the consultant is human after all and might have to share overwhelming anxiety with a colleague; that the consultant may have legal obligations to share some disclosures; and that he may act as 'message bearer' if he gets the clear impression that this is information that the patient wishes to be passed on. Within these parameters, the patient is then free to enjoy the confidentiality of the relationship, even if he is a minor fleeing from the 'trespass' of parents - although the Gillick rulings (following Gillick $v$. West Norfolk and Wisbech Area Health Authority, 1986, AC112) that cover this are vague enough to wake the child psychiatrist, sweating, in the middle of the night.

Voluntary sharing, of course, can be healing in itself and never more so than with self-help groups of similar sufferers in varying stages of their illness - consultants must not be so possessive as to neglect their value.

\section{Continuity of care v. separations}

Continuity of care is absolutely crucial. A change of doctor every six months is useless.

It's pointless seeing the same person if they don't remember you. I often get the feeling that he is trying to read my notes as I'm speaking.

Two patients with manic-depression

Given the importance placed on it, the ending of any individual consultant-patient relationship needs to be carefully managed. Both parties may have become dependent, to some extent, on each other; separation will be a form of bereavement. That separation process can be part of further healing, or a reinforcement of the problems for which the patient first sought help.
Such management requires the consultant to be aware of what has been called the 'rhythm of counselling'. We may adopt a simple, three-stage model of the helping relationship from identifying problems (helping the client to tell the story), through goal-setting (imagining a possible future), to action (achieving it) or break that up into a finer, eight-stage 'map' (Burnard, 1992). In either case, the consultant will need to help the patient lift from the deepest levels of disclosure to one at which he can safely close; and that goes for the shape of each individual session as well as the relationship as a whole (see Fig. 1).

At most, by working towards an explicit and agreed parting date, the issue of separation from the therapist may sometimes provoke material hitherto inaccessible to help. At the very least, endings are part of the developmental process. To finish too precipitately, or to allow the relationship to fray inconclusively at the edges, is to deny the learning involved.

But what of chronic illness? Here, of course, background continuity of support, from a consultant well-versed in the patient's history, is vital. And yet each illness episode may be seen as discrete and warrants a fresh appraisal of need. The consultant can never make assumptions on what has gone before. Patients are video films, not snapshots. They change, even if their consultant does not!

\section{Personal issues - empathy: forging the therapeutic alliance}

\section{Use of self v. use of techniques}

People are looking for and praying for a miracle.

I need my psychiatrist to be down-to-earth, with a pleasant but not patronising bedside manner.

Two self-help group members

Whatever the service has to offer, whatever treatment guidelines its practitioners follow, and whatever the contract established in the relationship between consultant and patient, it is within the mysterious climate of the therapeutic alliance that therapy will wither or flourish.

Any alliance is a two-way process, but traditional medicine has tended to focus on the quality of the patient more than that of the consultant. Patients are 'resistant' to treatment or 'non-compliant' with what the doctor orders. 'Heartsink' patients haunt the clinics with their belly-aches of 'non-organic origin'.

Recent British research (in the context of general medicine) has emphasised the mismatch between 
these patients' hopes and what the doctor has to offer (Sharpe et al, 1994). Small wonder, if we dislike people who want more than we can deliver. Sharpe et al suggest the liaison psychiatrist be called in as soon as possible; but there is no room for holier-than-thou attitudes here. We know how tempting it is for psychiatry to consign the 'manipulative', the 'attention-seeking' and the 'hysterical' to the diagnostic dust-bin.

In truth, the therapeutic 'fit' is a four-piece jigsaw, made up of personal qualities of both doctor and patient, the reality of the patient's expectations and the nature of the therapy that is available; consequently, the patient should expect the consultant to examine his own manner closely. There can be no disagreement about the core qualities of warmth, empathy and genuineness, but it is the patient's perception and experience of them that matters, not the assumption of their presence by the consultant. In other words, the consultant needs to listen to how the patient feels.

If the consultant is more than a mere techniquein-action, if he facilitates healing as much by personal magic as by knowledge and skill, what does that imply for medical education? The danger is that we assume that people either have that magic or they do not; but communication skills can be taught. It may be time to review the curricula of our medical schools in favour of the humanities (in all senses).

\section{Professional distance v. openness}

My ideal psychiatrist recognises that it is my life not his ... but is prepared to share his own life with $\mathrm{me}$. He is someone I can regard as a friend.

My doctor is honest, open and caring ... but he doesn't seem to realise with me that the impetus to get better comes from drugs.

Two fellow sufferers

If the patient cannot expect that her consultant know himself in the full analytical sense, she can at least expect him to be aware of the influence from his past. Only by disentangling his own history from that of the patient can he meet her with an unbiased attitude.

Openness with professional colleagues has wider implications. Freedom of communication within the team, of feelings as well as facts, offers the day-to-day support that we deserve as human beings as well as professionals. Caring for the carers has become a cliché only because it is true; the very least that patients can expect is that psychiatrists look after themselves enough to be able to look after others. This may include being aware of their own mental health problems and seeking help accordingly (Shooter, 1996).

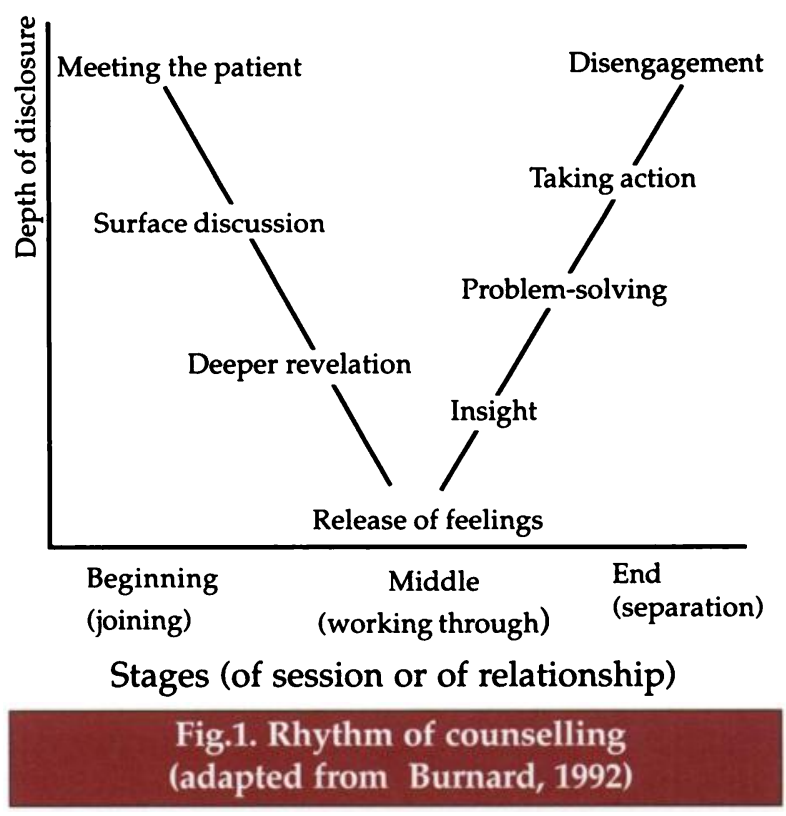

Moreover, there is much evidence (from the labour room to the death bed) that how we behave with each other is the model for how patients and their families behave in turn. In old-style professionalism, the practitioner dealt with his own upset by wearing two faces, public equanimity and private hurt. Not only did that often lead to burn-out, but also it encouraged patients to suppress their own feelings. The newer style promotes a model of sharing and support.

This is still a long way from the process of selfdisclosure, that sense of mutuality that arises out of exchanged experiences between patient and therapist. This is an advanced and controversial counselling skill. At worst, consultants who talk about themselves too much may sacrifice their value as a neutral, transference figure. At best, they risk boring their patients to distraction. In either case, they waste an opportunity to get closer to the patient on a human level.

\section{Honesty v. protectionism}

To be told the truth is to be prepared ... the more you understand, the better you are likely to cope with something that crops up and not be floored. You are mentally tougher to withstand the knocks.

User and hospital volunteer

What is helpful to one could very well disturb and distress another, especially should they be ill, isolated and alone with their fears.

Long-term user

And so, finally, to another aspect of openness - the free communication of what the consultant knows 
about the patient's condition and its progress. Here is another difficult tightrope to walk. Clearly, a patient's mastery of illness can only be achieved with information given lucidly and frequently, in a language that can be understood and in circumstances in which it can be properly received. It is all too easy for consultants to cocoon both self and patient in jargon, inside which:

the human reality of the lives of distressed men and women is in danger of getting lost altogether.

Rowe, 1994

A patient can expect the consultant to be sensitive in this as with any other quality; not to be honest for honesty's sake, irrespective of the patient's ability to cope. Legislation regarding freedom of information leaves the consultant with the responsibility of judging the right amount of information to give, when and how. And this too can be taught. There is no excuse for difficult news to be rushed, to be thrown precipitately at a patient sitting alone in an out-patient clinic and left to get home under its weight as best he can.

In this, as ever, the overriding task for the consultant, both in his own head and in direct collaboration with the patient, is to decide what is in the patient's interest. This tightrope is symbolic of all the rest. It is as tempting to leap for the safety net from this one as it is from all the others. The ability to stick with it and work out what are often painful compromises is what ensures that the process of illness and its treatment can be a positive, developmental opportunity for all concerned.

The good-enough consultant is one who is brave enough to walk these tightropes and to get back on each time, inevitably, there is a fall. It is, after all, no more than the patient could expect.

\section{References}

Adshead, G. (1995) Ethics of treatment and research in psychiatry. Current Opinion in Psychiatry, 8, 340-342.

Barker, D. A., Shergill, S. S., Higginson, I., et al (1996) Patients' views towards care received from psychiatrists. British Journal of Psychiatry, 168, 641-646.

Bowling, A. (1991) Measuring Health. A Review of Quality of Life Measurement Scales. Milton Keynes: Open University Press.

Burnard, P. (1992) Counselling Skills for Health Professionals. London: Chapman and Hall.

Heron, J. (1991) Helping the Client. A Creative Practical Guide. London: Sage Publications.

Horton, R. (1995a) The interpretive turn (commentary). Lancet, $346,3$.

- (1995b) Editorial: Maintaining confidentiality. Lancet, 346, 1172 Howe, D. (1993) On Being a Client. London: Sage Publications. Phillips, A. (1996) Terrors and Experts. London: Faber and Faber.

Rowe, D. (1994) Breaking the Bonds. London: Harper Collins.

Seedhouse, D. (1991) Liberating Medicine. Chichester: Wiley.

Sharpe, M., Mayou, R., Seagroatt, V., et al (1994) Why do doctors find some patients difficult to help? Quarterly Journal of Medicine, 87, 187-193.
Shooter, M. (1996) 'Physician, reveal thyself?' Psychiatric Bulletin, 20, 493-494.

\section{Multiple choice questions}

1. Interventions have been broadly classified as:
a authoritative and supportive
b confrontational and facilitative
c authoritative and facilitative
$\mathrm{d}$ informative and catalytic
e prescriptive and informative.

2. Outcome measures should:
a be valid
b reflect service policy
c rely on self-ratings
$\mathrm{d}$ be responsive to fine clinical changes
e cover quality of life issues.

3. Confidentiality:
a is not part of the Hippocratic Oath
b does not apply to information technology
c is not an issue in multi-disciplinary teams
$\mathrm{d}$ has not been considered by the BMA
e was the substance of the Gillick rulings.

4. The therapeutic alliance:
$a$ is part of the four principles of practice
b is influenced by the warmth, empathy and genuineness of the consultant
c can be part of medical school training
d has been researched by Sharpe
$\mathrm{e}$ is dependent on patient compliance.

5. In any relationship with a patient:

a the doctor should set a model of perfection

b the doctor should work towards patient empowerment

c the patient should have access to a complaints procedure

d the patient should never know about the doctor's own experiences

e the doctor should be governed by the Guidelines Programme.

\begin{tabular}{|c|c|c|c|c|}
\hline \multicolumn{5}{|c|}{ MCQ answers } \\
\hline 1 & 2 & 3 & 4 & 5 \\
\hline a $F$ & a $T$ & a $F$ & a $F$ & a $F$ \\
\hline b F & b F & b F & b $T$ & b $\mathrm{T}$ \\
\hline c $\mathrm{T}$ & c F & c F & c $\mathrm{T}$ & c $\mathrm{T}$ \\
\hline d F & d $T$ & d F & d $T$ & d F \\
\hline e F & e $T$ & e $T$ & e $F$ & e $F$ \\
\hline
\end{tabular}

